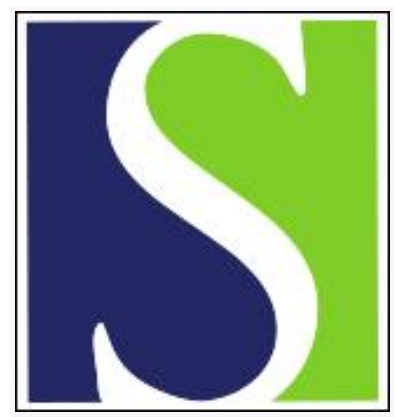

Scand J Work Environ Health 2015;41(4):347-355

https://doi.org/10.5271/sjweh.3504

Published online: 27 May 2015, Issue date: 01 Jul 2015

Worktime control access, need and use in relation to work-home interference, fatigue, and job motivation

by Nijp HH, Beckers DGJ, Kompier MAJ, van den Bossche SNJ, Geurts SAE

Among a quasi-representative sample of Dutch employees, we assessed not only prevalence of access to an extensive range of worktime control (WTC) sub-dimensions, but also need for, and use of WTC, as well as motives for using WTC and the mismatch between WTC need and access. The associations between these variables and employees' well-being were then studied.

Affiliation: Radboud University, Behavioural Science Institute, Department of Work \& Organizational Psychology, Montessorilaan 3, 6525 HR Nijmegen, The Netherlands. H.Nijp@psych.ru.nl

Refers to the following texts of the Journal: 2012;38(4):327-336

2012;38(4):291-297 2012;38(4):299-313 2012;38(4):314-326

2009;35(3):163-179 2006;32(6):502-514 2006;32(6):421-430

$1999 ; 25(2): 85-99$

The following articles refer to this text: 2020;46(5):469-479; 2021;47(3):181-190; 2021;47(8):619-627

Key terms: employees' need; fatigue; job motivation; schedule control; well-being; work arrangement; work-home interference; work-life balance; working time; working time flexibility; worktime control; worktime control access

This article in PubMed: www.ncbi.nlm.nih.gov/pubmed/26010748

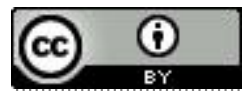




\title{
Worktime control access, need and use in relation to work-home interference, fatigue, and job motivation
}

\author{
by Hylco H Nijp, MSc, ${ }^{1}$ Debby GJ Beckers, PhD, ${ }^{1}$ Michiel AJ Kompier, PhD, ${ }^{1}$ Seth NJ van den Bossche, \\ $M S c,{ }^{2}$ Sabine AE Geurts, PhD ${ }^{1}$
}

\begin{abstract}
Nijp HH, Beckers DGJ, Kompier MAJ, van den Bossche SNJ, Geurts SAE. Worktime control access, need and use in relation to work-home interference, fatigue, and job motivation. Scand J Work Environ Health. 2015;41(4):347355. doi:10.5271/sjweh.3504
\end{abstract}

Objective Worktime control (WTC) has been suggested as a tool to reduce employees' work-home interference and fatigue and to improve job motivation. The purpose of this study was twofold: (i) to examine the prevalence of employees' need for, access to, and use of WTC, as well as the incongruence between need for and access to WTC (ie, mismatch); and (ii) to examine the associations of this mismatch and the use of WTC with employees' work-home interference (WHI), fatigue and job motivation.

Methods Questionnaire data were collected among a large $(\mathrm{N}=2420)$ quasi-representative sample of Dutch employees. The prevalence of WTC need, access, use, and mismatch was assessed by means of descriptive statistics. Associations with employees' outcomes were assessed by analyses of covariance.

Results The need for WTC was highly prevalent. For many employees, we observed a negative mismatch between access to and need for WTC (ie, access $<$ need). A negative WTC mismatch was associated with relatively high levels of WHI and fatigue, and lower job motivation. The use of WTC was also highly prevalent, but no meaningful associations were found with the outcome variables.

Conclusions It is relevant to examine WTC comprehensively, that is, to include measurements of employees' need for and access to WTC and assess employees' (mis)match between components of WTC. For practice, we recommend to introduce WTC on an organizational level and assess employees' need for WTC on an individual basis.

Key terms employees' need; schedule control; well-being; work arrangement; work-life balance; working time flexibility; working time.

Demanding working hours and irregular shiftwork arrangements that characterize modern work are linked to a range of unfavorable outcomes (1-3). Several studies suggest that employees' control over working hours [ie, worktime control (WTC)] may attenuate such negative effects (4-6). Employees who report relatively high levels of WTC seem better able to regulate their time demands (ie, time regulation) and recovery needs (ie, recovery-regulation), allowing them to combine work and domestic obligations and manage fatigue by taking sufficient rest (7). Additionally, having control over one's working hours meets the basic human need for autonomy (ie, self-determination) and can have beneficial effects on motivation and well-being (eg, 8-13). As such, WTC may be a powerful instrument to help employees in managing high work demands and in combining work and domestic obligations.

A recent review showed that, although many studies found evidence for favorable associations between WTC and work-nonwork balance, health and well-being, and job related outcomes, there were also inconsistent findings (14). We propose three explanations for such inconsistencies. First, the exact measurement of WTC differs strongly among studies (eg, compare 15-18). Only a few studies measured a full range of WTC sub-dimensions (ie, control over starting- and ending times, leave, breaks, specific working days, the distribution of working hours over the week, and overtime work). These variations in measurements of WTC may impact the associations with

1 Behavioral Science Institute, Radboud University, Nijmegen, The Netherlands.

2 TNO department of Work, Health \& Care, Hoofddorp, The Netherlands.

Correspondence to: Hylco Nijp, Radboud University, Behavioural Science Institute, Department of Work \& Organizational Psychology, Montessorilaan 3, 6525 HR Nijmegen, The Netherlands. [E-mail: H.Nijp@psych.ru.nl] 
potential outcomes. Second, associations of reported WTC and employees' outcomes are likely to depend on employees' need for WTC. It is likely that the fit between access to and need for WTC (ie, 'WTC match') is more important for potential employees' outcomes than just the reported availability of WTC. Thirdly, it is often unclear whether employees who report to have access to WTC actually use WTC, which could be a prerequisite for beneficial effects to occur $(19,20)$.

Based on these points, it is relevant to adopt a WTC measurement that involves a full range of specific WTC sub-dimensions to study employees' need for, access to, and use of WTC and to pay specific attention to the potential (mis)match between the need for and access to WTC [hereafter referred to as "WTC (mis)match"] (7). Therefore, the first aim of this paper was to examine the prevalence of (i) various WTC sub-dimensions, (ii) employees' need for, access to, and use of WTC, and (iii) the WTC mismatch. Our second aim was to examine the relations of WTC mismatch and WTC use with the potential outcomes.

Aim 1: Prevalence of WTC need, access, use, and (mis) match

Although WTC is becoming more prevalent $(21,22)$, and modern organizational interventions that incorporate WTC gain popularity (eg, self-scheduling, 23-27; boundaryless work, 28-30), it is still unknown whether access to WTC differs for various WTC sub-dimensions and to what extent such WTC sub-dimensions are needed or used by employees. Additionally, several studies stress the importance of a proper fit between individual needs and working hours of employees (eg, 24, 30-35), but WTC has not yet been researched from such an "individual match" principle.

Our first research questions are therefore:

- RQ1: What is the prevalence of WTC need, access, and use?

- RQ2: What is the prevalence of WTC mismatch?

In answering these questions, prevalences will be reported separately for shift and day workers. The organization of working time differs strongly between shift and day workers (36), which has been found to influence levels of WTC (6). Moreover, various studies have shown that especially shift workers are at risk for adverse health effects as a result of their abnormal working times (eg, 1, 36-41).

Aim 2: WTC in relation to employees' work-home interference, fatigue, and job motivation

As WTC can be beneficial through different mechanisms (ie, time-regulation, recovery-regulation and self-determination) (6), we focus on three outcomes that match these diverse mechanisms: work-home interference (WHI), fatigue, and job motivation (ie, an employees' willingness to invest sustained and directed effort for accomplishing work; 9, see also 10). To examine the associations of WTC mismatch and WTC use with our outcome variables, our next research questions are as follows:

- RQ3: How is WTC mismatch related to employees' WHI, fatigue and job motivation?

- RQ 4: How is WTC use related to employees' WHI, fatigue, and job motivation?

In line with person-environment fit models $(42,43)$ and studies on fit between working-time preferences and working hours $(24,31-35)$, lack of access to WTC is expected to have the most unfavorable impact on employees with a high need for WTC. We, therefore, hypothesize that employees with a negative mismatch (need $>$ access) report higher WHI and fatigue and lower job motivation than employees with a WTC match or a positive mismatch (access $>$ need). As favorable effects of WTC are more likely to occur when WTC is actually being applied $(19,20)$, we expect WTC use to have an additional favorable effect over WTC access alone. Thus, we hypothesize that employees with high use of WTC report lower WHI and fatigue and higher job motivation than employees with low WTC use.

\section{Method}

\section{Sample and procedure}

Data were collected in October/November 2012 through an online questionnaire sent to a large sample of Dutch employees with various occupational backgrounds. The sample was derived from a survey study on work characteristics (National Survey Working conditions, in Dutch: NEA), conducted by the Dutch Organization for Applied Scientific Research (TNO) and the Central Bureau for Statistics Netherlands (44) in $2010(\mathrm{~N}=23$ 788). All respondents who (i) completed the online version of the NEA, and (ii) also agreed to participate in subsequent studies, were contacted for participation in our study $(\mathrm{N}=5504)$. Reminders were sent $2-3$ weeks after the initial invitation. In total, 2420 respondents completed the questionnaire (response rate $=44 \%$ ). Respondents who were no longer employed at the time of participation in our study $(\mathrm{N}=179)$ were excluded. Also respondents who worked $<12$ contractual hours per week $(\mathrm{N}=67)$ or $>48$ (the legal maximum) $(\mathrm{N}=4)$ were excluded. This resulted in a final sample of 2170 respondents with a fulltime or part-time appointment $\left(43.6 \%\right.$ female; $\mathrm{M}_{\text {age }}$ 46.06 years; range $16-67$ years). Respondents worked 33.56 contractual hours per week on average [standard deviation (SD) 7.41$]$, and $16.0 \%(\mathrm{~N}=347)$ worked in 
shifts. Moreover, $82.1 \%$ were married or cohabiting, and $47.6 \%$ had children living in the household. Although the current sample was derived from a random selection of Dutch employees, analysis of representativeness (see online supplement) revealed that highly educated workers were somewhat overrepresented in our study (44).

\section{Measures}

Our WTC measurement included six items on WTC need, six items on WTC access, and four items on WTC use. A complete overview of all items can be found in table 1 . Three items on WTC were self-developed, and three items were based on Van Veldhoven and Sluiter (45).

Items on WTC need and access were presented to all respondents. Items on WTC use were presented conditionally: As WTC access is a prerequisite for WTC use, questions on use for each WTC sub-dimension were only asked when a respondent first indicated to have access to the corresponding sub-dimension of WTC, at least to a reasonable extent (score 3-5).

WHI was measured with six items from the Nijmegen Work-Home Interaction Survey (46; Dutch version). We distinguished between three strain-based WHI items (eg, "How often does it happen that your work obligations make it difficult for you to feel relaxed at home") and three time-based WHI items (eg, "How often does it happen that your work schedule makes it difficult for you to fulfil your domestic obligations"). Responses were provided on a 4-point Likert scale ( $1=$ almost never to $4=$ almost always).

Fatigue was measured by a combination of four items from the Fatigue Assessment Scale (47) and one item ("In general, I only start to feel relaxed on the second non-working day") from the Questionnaire for Experience and Assessment of Work (Dutch version; 48). Answers were provided on a 5-point Likert scale ( $1=$ almost never to $5=$ almost always $)$.

Job motivation was measured by a single item ("How motivated are you with regard to your work?"), with responses being provided on a 10-point Likert scale ( $1=$ not motivated at all to $10=$ very much motivated).

Shiftwork was assessed by asking whether respondents worked (i) shifts or (ii) night shifts (yes, regularly; yes, sometimes; or no). Respondents who answered no to both items were categorized as day workers $(\mathrm{N}=1823)$, other respondents were categorized as shift workers $(\mathrm{N}=347)$. We included respondents' gender, age, education, children living in the household, cohabiting- or marital status and job sector (dummy coded) as control variables. All scales' Cronbach alpha's were satisfactory to high (see table 2).

\section{Statistical analysis}

To analyze the prevalence of WTC need, access, and use
(RQ1), means and SD were calculated. Moreover, WTC need, access, and use were dichotomized for each WTC sub-dimension: Respondents who indicated to need a certain sub-dimension "not at all" (score 1) or only "to a limited degree" (score 2) were categorized as low. Respondents who indicated to need a certain sub-dimension to a "reasonable" to "very strong" degree (score 3 to 5) were categorized as high. The same dichotomization procedure was applied to classify respondents as low versus high regarding access to and use of each WTCsub-dimension. Frequency analyses were conducted to examine the prevalence of the various high versus low groups for each WTC sub-dimension.

To answer RQ2 (prevalence of WTC mismatch), we created a WTC mismatch variable by subtracting respondents' WTC need from his/her WTC access (both ranges: 1-5) per WTC sub-dimension. Values $<0$ were indicative of a negative mismatch (ie, WTC need $>$ access), values of 0 were indicative of a WTC match (ie, WTC need $=$ access), and values $>0$ were indicative of a positive WTC mismatch (ie, WTC need $<$ access). Frequency

Table 1. Full measurement of worktime control (WTC) need, access, and use. Response scale for all items: $1=$ "(almost) not at all"; 2="to a limited extent"; $3=$ "to a reasonable extent"; 4="to a high extent"; $5=$ "to a very high extent".

WTC need $(\alpha=0.85)$

To what extent do you have the need to ..

1 .. determine the starting and ending times of your working day yourself?

2 .. determine yourself when to take a break?

3 .. take leave (day off, holidays) when you want?

$4 \quad$.. determine yourself on which days to work?

5 .. determine the distribution of your working hours over the work week yourself?

$6 \quad$.. determine yourself whether to work overtime?

WTC access $(\alpha=0.88)$

To what extent do you have the possibility to .

$1^{\text {a }} .$. determine the starting and ending times of your working day yourself?

$2^{\text {a }} \quad$. determine yourself when to take a break?

$3^{\text {a }} \quad .$. take leave (day off, holidays) when you want?

$4 \quad$.. determine yourself on which days to work?

5 .. determine the distribution of your working hours over the work week yourself?

$6 \quad$.. determine yourself whether to work overtime?

WTC use ${ }^{\mathrm{b}}(\alpha=0.74)$

To what extent do you make use of your possibility to ..

1 .. determine the starting and ending times of your working day yourself?

2 .. determine yourself when to take a break?

3 .. take leave (day off, holidays) when you want?

$4 \quad$.. determine yourself on which days to work?

a Item based on Van Veldhoven and Sluiter (45).

${ }^{b}$ Having control over whether or not to work overtime (ie, access) means that employees decide for themselves whether they work overtime or not. Because making any choice between working overtime or not can be regarded as 'use' of control over overtime, use of overtime was not specifically measured. Because (i) use of control over distribution of working hours can be regarded as a combination of use of starting and ending times and control over which days to work, and because (ii) we wanted to avoid an overly lengthy questionnaire, we did not measure use of distribution of working hours over the week. 
analyses were conducted to examine the prevalence of the various (mis)match groups for each WTC sub-dimension.

Before examining RQ3 (association WTC mismatch and outcomes), we averaged every respondent's mismatch values over all WTC sub-dimensions. Respondents were then categorized into one of three groups: a positive mismatch group (mean mismatch values ranging from $1-4 ; \mathrm{N}=167$ ), a match group (with mean mismatch values ranging from $-0.99-0.99 ; \mathrm{N}=1332$ ), or a negative mismatch group (with mean mismatch values ranging from $-1--4 ; \mathrm{N}=609$ ). For RQ4 (association WTC use and outcomes), we assigned respondents to either a low- (mean WTC use $<3.00 ; \mathrm{N}=489$ ) or high (mean WTC use $\geq 3.00$; $\mathrm{N}=1295$ ) use group ( $3=$ "reasonable degree of use").

To examine the relationships between WTC mismatch and employees' outcomes (RQ3), we conducted four analyses of covariance (ANCOVA) (ie, for each dependent variable: strain-based WHI, time-based WHI, fatigue, and job motivation) with the three WTC (mis) match groups as between subject factor. ${ }^{1}$ The same analyses were conducted to assess the relationship between the two WTC use groups (low versus high) and the outcome variables. The control variables (ie, gender, age, education, marital or cohabiting status, children living in the household and job sector), were included as covariates in all ANCOVA analyses.

\footnotetext{
${ }^{1}$ Because we want to rule out the possibility that the relationships with the outcomes were dependent on our categorization procedure, we replicated the analyses by using regression analyses with WTC mismatch and WTC use as continuous predictors. These additional analyses corroborated our findings (output can be retrieved from the first author). Moreover, ANCOVA analyses with broader and narrower defined match/mismatch groups confirmed our initial findings, indicating that our findings are robust for variations in classification. The categorical approach was preferred for its fit with the first aim of the paper, that is, providing prevalences of WTC access, need, use, and mismatch.
}

\section{Results}

Descriptive statistics and correlations among the study variables are presented in table 2. WTC mismatch showed stronger correlations with all four outcome variables than the separate measurements of access to and need for WTC. WTC use was not substantially correlated with any of these outcomes. In general, a more negative mismatch was correlated with higher WHI, higher fatigue, and lower job motivation.

\section{RQ1: Prevalence of WTC need, access, and use}

Figure 1 shows frequencies of WTC need, access, and use per WTC sub-dimension for day and shift workers, respectively. On average, day workers reported a reasonable WTC need (mean 3.20, SD 1.01), with a large proportion reporting a reasonable-to-very-high WTC need in general $(63.2 \%$ with mean score $\geq 3.00)$. Need for leave control was reported most frequently $(88 \%)$ among day workers, whereas the need for all other WTC sub-dimensions was reported by about two-third of the day workers $(63.1 \%$ to $70.7 \%)$.

Among shift workers, WTC need was on average less prevalent (mean 2.76 , SD $0.92 ; 45.5 \%$ with mean score $\geq 3.00$ ), but still $40.3-82.7 \%$ of shift workers had reasonable-to-very-high need for WTC, depending on the specific sub-dimension. Control over leave was most frequently needed $(82.7 \%)$, and control over daily starting and ending times least frequently $(40.3 \%)$.

For both day and shift workers, access to WTC was less prevalent than WTC need. Almost half of day workers had a reasonable-to-very high WTC access on average ( $47.4 \%$ with mean score $\geq 3.00$; mean 2.85 ; SD 1.04). The majority of day workers reported limited or no control over which days to work (58.3\%), and the

Table 2. Means and correlations of main study variables ( $\mathrm{N}=2169)$. Values on diagonal represent Cronbach's values. [SD=standard deviation; WTC=worktime control; WHI=work-home interference]

\begin{tabular}{|c|c|c|c|c|c|c|c|c|c|c|c|}
\hline Variable & M & SD & Range & 1 & 2 & $3^{a}$ & 4 & 5 & 6 & 7 & 8 \\
\hline \multicolumn{12}{|l|}{ Worktime control } \\
\hline 1. WTC need & 3.13 & 1.01 & $1-5$ & 0.85 & & & & & & & \\
\hline 2. WTC access & 2.72 & 1.03 & $1-5$ & $0.49 c$ & 0.88 & & & & & & \\
\hline 3. WTC use ${ }^{a}$ & 3.30 & 0.88 & $1-5$ & $0.26^{c}$ & $0.24^{c}$ & 0.74 & & & & & \\
\hline 4. WTC mismatch ${ }^{\mathrm{b}}$ & -0.41 & 1.05 & $-4-4$ & $0.47^{c}$ & $-0.53^{c}$ & $0.05^{d}$ & 0.82 & & & & \\
\hline \multicolumn{12}{|l|}{ Well-being indicators } \\
\hline 5. Time-based WHI & 1.55 & 0.56 & $1-4$ & $0.14^{c}$ & $-0.18^{c}$ & -0.04 & $-0.31^{c}$ & 0.77 & & & \\
\hline 6. Strain-based WHI & 1.59 & 0.55 & $1-4$ & $0.19^{c}$ & -0.04 & $-0.10^{\mathrm{e}}$ & $-0.21^{c}$ & $0.47^{c}$ & 0.79 & & \\
\hline 7. Fatigue & 2.14 & 0.80 & $1-5$ & $0.12^{c}$ & $-0.18^{c}$ & -0.07 e & $-0.30^{c}$ & $0.36^{c}$ & $0.56^{c}$ & 0.82 & \\
\hline 8. Job motivation & 7.84 & 1.34 & $1-10$ & $-0.07^{d}$ & $0.14^{c}$ & 0.03 & $0.21^{c}$ & $-0.11^{c}$ & $-0.21^{c}$ & $-0.29 c$ & - \\
\hline
\end{tabular}




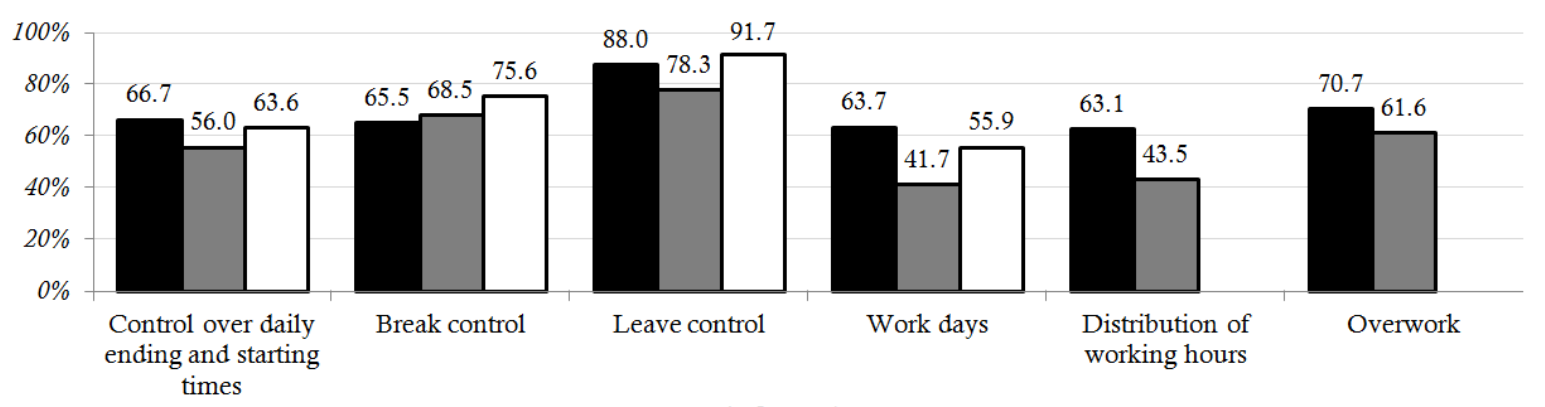

Shift workers:

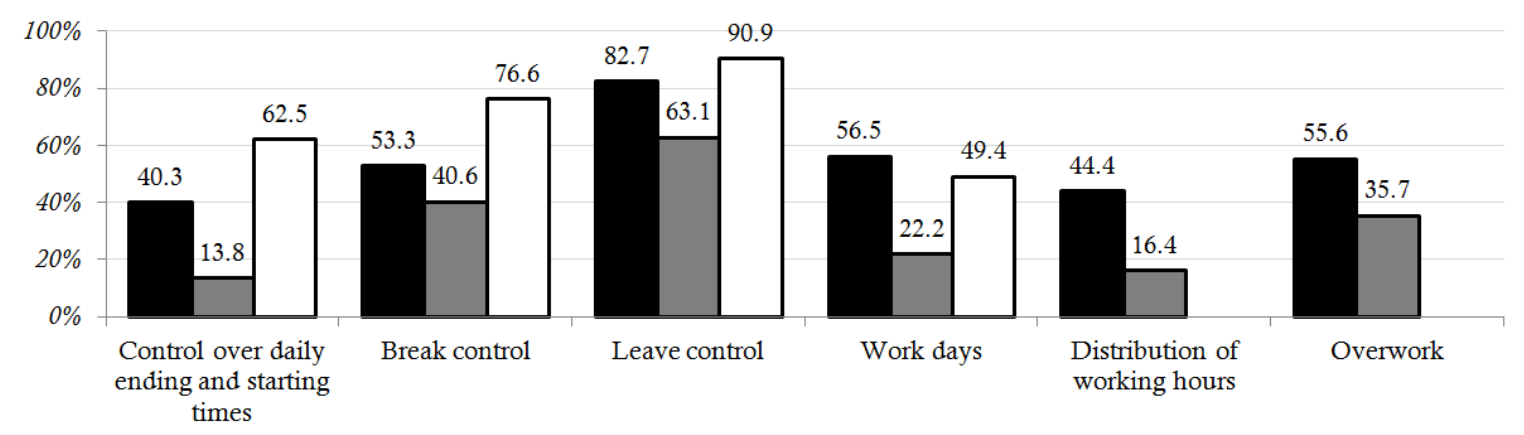

- Reasonable to very high need for WTC (\%) םReasonable to very high access to WTC (\%) पReasonable to very high use of WTC (\%)

Figure 1. Prevalence of worktime control (WTC) need, access, and use per WTC sub-dimension among day ( $N=1823$ ) and shift (N=347) workers . One missing response on WTC need ( $\mathrm{N}=1822)$ among day workers. WTC use was assessed only among respondents who had at least reasonable access to the corresponding WTC sub-dimension (N ranges from 760-1428 for day workers and 48-219 for shift workers). Numbers are percentages.

distribution of working hours over the week (56.5\%). Also substantial proportions of workers reported limited-to-no control over starting and ending times of the workday and working overtime (44.0\% and $38.4 \%$, respectively).

Among shift workers, prevalence of WTC access was markedly lower as compared to day workers, with only one out of eight shift workers having reasonable-tovery-high access to WTC on average (12.1\% with mean score $\geq 3.00$; mean 2.07; SD 0.72). A large majority of shift workers reported limited or no control over starting and ending times, distribution of hours over the work week, and the specific working days $(86.2 \%, 83.6 \%$, and $77.8 \%$ respectively).

WTC use was reasonably prevalent among day workers who had WTC access $(\mathrm{N}=1584$; mean 3.30; SD $0.88 ; 71.9 \%$ with mean score $\geq 3.00$ ). Use of WTC was most frequently reported for leave control (91.7\%), and least frequently for control over starting- and ending times $(63.6 \%)$ and control over which days to work $(55.9 \%)$. This pattern was very similar for shift workers with access to WTC ( $\mathrm{N}=250$; mean 3.33 ; SD 0.88; $78.4 \%$ with mean score $\geq 3.00$ ).

\section{RQ2: Prevalence of WTC (mis-)match}

This (mis)match pattern for different WTC-sub-dimensions was similar among day and shift workers (figure 2). For both groups, a negative mismatch (ie, need $>$ access) was most frequently found for control over leave, which days to work, and the distribution of working hours over the work week. A negative mismatch was least prevalent for break control. On almost all WTC sub-dimensions, a negative mismatch was more prevalent than either a match or a positive mismatch. Overall, a negative mismatch was more prevalent among shift workers (mean $50.2 \%$ ) as compared to day workers (mean $41.1 \%$ ).

\section{RQ3: WTC mismatch in relation to outcomes}

ANCOVA analyses showed significant differences between the three WTC (mis)match groups on the four outcome variables (table 3). Respondents in the negative mismatch group reported higher strain-based WHI (mean 1.76), higher time-based WHI (mean 1.78), higher fatigue (mean 2.46) and lower job motivation (mean 7.49) as compared to respondents in the positive mismatch group (with mean 1.50, 1.35, 1.94, and 8.14 respectively) or the match group (with mean 1.53 , 
Day workers

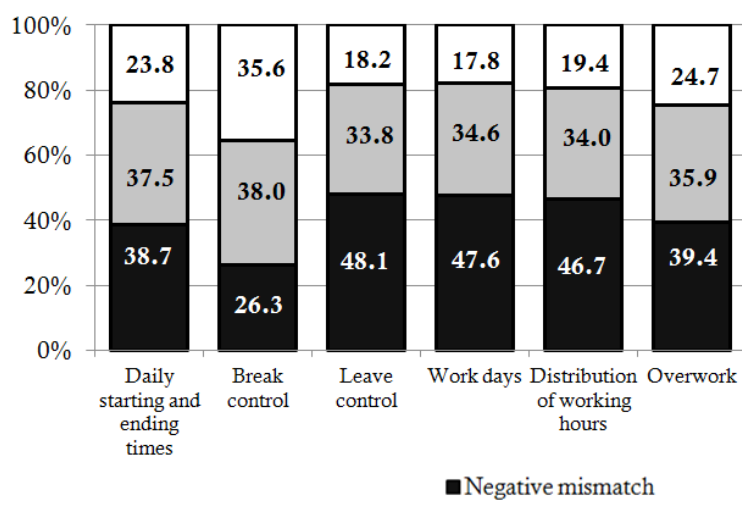

Shift workers

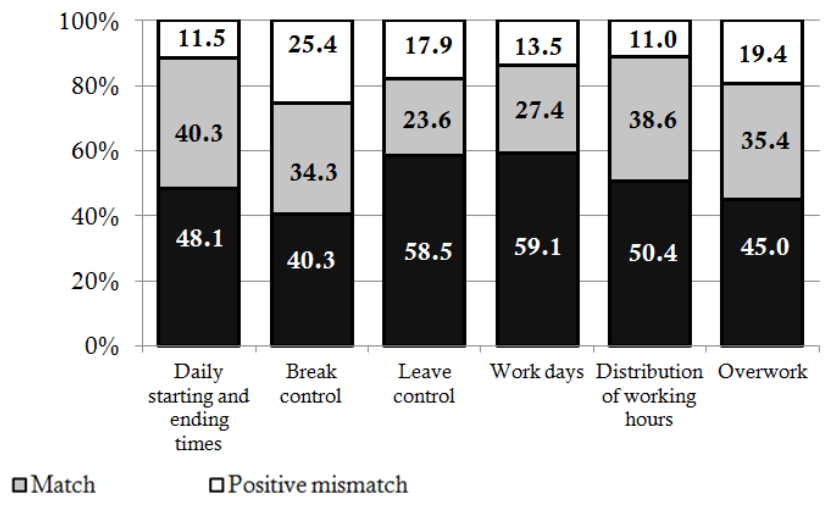

Figure 2. Prevalence of worktime control (WTC) mismatch per WTC sub-dimension of WTC among day (N=1822) and shift (N=347) workers. Mismatch was calculated as WTC access minus need; Negative mismatch: WTC need >WTC access; Match: WTC need=WTC access; Positive mismatch: WTC need <WTC access. Numbers are percentages.

Table 3. Outcome variables as a function of worktime control (WTC) mismatch (ANCOVA). Covariates: gender, age, education, marital- or cohabiting status, children living in the household and job sector (dummy coded: crafting, transport, administrative, commercial, services, healthcare, education, specialist, agrarian). Post-hoc analyses: Games-Howell test; variable ranges between parentheses; lower sample size results from missing cases on covariates [ie, 16 implausible responses for age; 46 cases without data on "marital- or cohabiting status" and "children living in the household". WHI=work-home interference]

\begin{tabular}{|c|c|c|c|c|c|}
\hline & \multicolumn{3}{|c|}{ Means per group } & \multirow[t]{2}{*}{$F(2,2091)$} & \multirow[t]{2}{*}{ Partial Eta ${ }^{2}$} \\
\hline & $\begin{array}{l}\text { A. Positive mismatch } \\
\text { (need<access) } \\
(\mathrm{N}=167)\end{array}$ & $\begin{array}{c}\text { B. Match } \\
\text { (need } \approx \text { access }) \\
(\mathrm{N}=1332)\end{array}$ & $\begin{array}{l}\text { C. Negative mismatch } \\
\text { (need >access) } \\
(\mathrm{N}=609)\end{array}$ & & \\
\hline Strain-based WHI (1-4) & 1.49 a & $1.53^{\mathrm{a}}$ & $1.76^{b, c}$ & $46.08^{d}$ & 0.04 \\
\hline Time-based WHI (1-4) & $1.35^{a, c}$ & $1.46^{a, b}$ & $1.78^{b, c}$ & $93.30^{d}$ & 0.08 \\
\hline Fatigue (1-5) & 1.94 a & $2.02^{\text {a }}$ & $2.46 \mathrm{~b}, \mathrm{c}$ & $70.42^{d}$ & 0.06 \\
\hline Job motivation (1-10) & $8.14^{\text {a }}$ & $7.98^{\text {a }}$ & $7.49 b, c$ & $35.89 \mathrm{~d}$ & 0.03 \\
\hline
\end{tabular}

a Mean differs significantly from group $c$.

${ }^{\mathrm{b}}$ Mean differs significantly from group a.

c Mean differs significantly from group $b$.

d $\mathrm{P}<0.001$.

$1.46,2.02$, and 7.98 respectively). These results are consistent with hypothesis 1 . Effect sizes were small to medium (all partial $\eta^{2} \leq 0.08$; see table 3 ).

\section{RQ4: WTC use in relation to outcomes}

ANCOVA analyses showed no significant differences between the high versus low WTC use groups with regard to time-based WHI $[\mathrm{F}(1,1768)=1.25 ; \mathrm{P}=0.26]$, fatigue $[\mathrm{F}(1,1768)=3.30 ; \mathrm{P}=0.07]$, and job motivation $[\mathrm{F}(1,1768)=1.80 ; \mathrm{P}=0.18]$. Respondents in the high WTC use group only reported significantly lower strain-based WHI (mean 1.54) as compared to respondents in the low WTC use group [mean 1.63; F(1, $1768)=11.11 ; \mathrm{P}=0.001]$. However, the proportion of explained variance in strain-based WHI was negligibly small $\left(\right.$ partial $\left.\eta^{2}=0.01\right)$. Hence, hypothesis 2 did not receive support.

\section{Discussion}

Previous research on WTC merely concentrated on access to WTC without taking into account employees' need for WTC and actual use of it. In this paper, we studied WTC need and use above and beyond WTC access and measured a full range of six WTC sub-dimensions. We argued that this richer conceptualization of WTC provides a better understanding of its prevalence and of its relation with WHI, fatigue, and job motivation.

With regard to prevalence of WTC (aim 1), our results showed that a large majority of Dutch day workers as well as a substantial proportion of shift workers had a reasonable-to-very-high need for WTC.

WTC access was generally less prevalent than WTC need for day, but even more so for shift workers. As a consequence, a negative mismatch between need for and 
access to WTC was prevalent among day and especially shift workers. When access is provided, a large majority of both day and shift workers make use of WTC.

As hypothesized, employees who were categorized in the negative mismatch group reported somewhat higher WHI and fatigue and lower job motivation in comparison to employees who were categorized in the match group or positive mismatch group. Whether WTC use was high or low did not make a difference in terms of outcome variables. These results might indicate that having access to WTC is a more decisive factor for WHI, fatigue, and job motivation than the actual use of WTC. However, alternative explanations could account for the suggested lacking impact of WTC use on potential outcomes, as will be explained below.

\section{Theoretical implications}

Our finding that employees with a negative mismatch between need for and access to WTC reported higher WHI and fatigue and lower job motivation than employees with a match or a positive mismatch, is in line with the literature on person-environment fit (eg, 42, 43) that suggests that not so much job characteristics per se, but their congruence with individual needs is decisive for employees' well-being. Although it has previously been posed that consideration of individual preferences is essential in work-hour research $(24,31-35)$, as yet such individual preferences have not been studied within the context of worktime control. The current study contributes to theory by demonstrating how individual needs play a role in the association between available WTC opportunities and employees' outcomes.

The use of WTC was not, as we expected, associated with more favorable employee outcomes. However, we cannot conclude from this finding that the use of WTC is not beneficial for workers in terms of WHI, fatigue and job motivation. It might be that the non-users simply have nothing to gain from the use of WTC opportunities in terms of these outcomes. It would be interesting to also consider the "need to use WTC" in future studies.

The relatively high prevalence of negative WTC mismatch among shift compared to day workers adds to the literature on the unfavorable effects of shiftwork on employee health. Due to the abnormal working hours, shiftwork arrangements are related to sleep disorders, fatigue and health problems such as cardiovascular and gastrointestinal disease or cancer (eg, 1, 36-41, 49). Introducing interventions that create some WTC opportunities for shift workers as well, might reduce the large discrepancy between access to and need for WTC among this group. This might be an important step to limit the adverse effects of working hours on shift workers' health.

Our finding that a negative WTC mismatch is more prevalent among shift than day workers implies that WTC is more inherent in some jobs than others. Although a detailed analysis of job sector or type was beyond the scope of this paper, explorative post-hoc analyses revealed that some job sectors had higher WTC access or need than others. These effects were small however, and the distinction between shift versus day work explains notably more variance in WTC access.

\section{Study assets and limitations}

This study was the first to provide an overview of employees' need for, access to, and use of various WTC sub-dimensions. Our finding that a negative WTC mismatch between access to and need for WTC is associated with higher WHI and fatigue and lower job motivation supports the necessity of an integrated view on WTC. The current study provides researchers with a comprehensive WTC measurement scale that can be used in future studies that aim for a broad perspective on WTC. Finally, the results were based on a large and heterogeneous sample of Dutch employees, favoring the generalizability of our conclusions.

However, some limitations should be noted as well. First of all, the cross-sectional nature of this study does not allow for any causal inferences. Bidirectionality of some associations under study is plausible though. For example, high levels of fatigue or WHI may increase the need for WTC, which in turn may increase the likelihood of a negative mismatch, especially when access to WTC is limited. Following this reasoning, our outcome variables may have possibly contributed to WTC mismatch. In order to assess the causal direction of associations between the various components of WTC and employees' outcomes and find out whether increments in WTC access and use are especially beneficial for workers with a high need for WTC, future intervention studies are strongly needed.

Highly educated employees were somewhat overrepresented in the current study. This may reduce the generalizability of findings. The relatively high education levels, and the associated higher job levels, may have inflated the prevalence of WTC as reported in this paper $(21,50)$. If so, in reality the proportion of workers with a negative mismatch between access to and need for WTC may be even higher. This adds to the urgency to increase the availability of WTC opportunities.

\section{Concluding remarks}

This study provided evidence that the majority of day and shift workers in the Netherlands WTC highly need WTC, but that - for many workers - the available WTC opportunities do not match their needs. Such a negative mismatch between need for and access to WTC is related to higher WHI and fatigue, and lower job motivation. 
Our findings suggest that many workers might benefit from available WTC opportunities, but that simultaneously individual needs for WTC should be taken into consideration. This implies that WTC interventions on an organizational level, such as boundaryless work (28-30) or self-scheduling (eg, 23-27), should not be expected to be beneficial for every individual, and that tailor-made implementations based on need assessments might be more effective in terms of employees' workhome balance, energy levels, and motivation (7).

\section{Acknowledgments}

The authors would like to thank ZonMw for the funding. (project number 20801003).

\section{References}

1. Härmä M. Workhours in relation to work stress, recovery and health. Scand J Work Environ Health. 2006;32:502-14. http:// dx.doi.org/10.5271/sjweh.1055.

2. Kompier MAJ. New systems of work organization and workers health. Scand J Work Environ Health. 2006;32:421-30. http:// dx.doi.org/10.5271/sjweh.1048.

3. Pereira MC, Coelho F. Work Hours and Well Being: An Investigation of Moderator Effects. Soc Indic Res. 2013;111:235-53. http://dx.doi.org/10.1007/s11205-0120002-3.

4. Geurts SAE, Beckers DGJ, Taris TW, Kompier MAJ, Smulders PGW. Worktime demands and work-family interference: does worktime control buffer the adverse effects of high demands? J Bus Ethics. 2009;84:229-41. http://dx.doi.org/10.1007/ s10551-008-9699-y.

5. Hughes EL, Parkes, KR. Work hours and well-being: The roles of work-time control and work family interference. Work Stress. 2007;21(3):264-78. http://dx.doi. org/10.1080/02678370701667242.

6. Nätti J, Oinas T, Härmä M, Anttila T, Kandolin I. Combined Effects of Shiftwork and Individual Working Time Control on Long-Term Sickness Absence: a Prospective Study of Finnish Employees. J Occup Environ Med. 2014;56(7):732-8. http:// dx.doi.org/10.1097/JOM.0000000000000176.

7. Beckers DGJ, Kompier MAJ, Kecklund G, Härmä M. Worktime control: Theoretical conceptualization, current empirical knowledge, and research agenda. Scand J Work Environ Health. 2012;38(4):291-7. http://dx.doi.org/10.5271/sjweh.3308.

8. Deci EL, Ryan RM. Self-determination theory: A macrotheory of human motivation, development, and health. Canad Psych. 2008;49:182-5. http://dx.doi.org/10.1037/a0012801.

9. Geen RG. Human motivation: A social psychological approach. Belmont, CA, US: Thomson Brooks/Cole
Publishing Co; 1995.

10. Mitchell TR, Daniels D. Motivation. In: Borman WC, Ilgen DR, Klimoski RJ, editors. Handbook of Psychology, vol.12, Industrial and Organizational Psychology. New Jersey: John Wiley; 2003. p. 225-54. http://dx.doi. org/10.1002/0471264385.wei1210.

11. Spector PE. Employee control and occupational stress. Curr Dir Psychol Sci. 2002;11:133-6. http://dx.doi.org/10.1111/14678721.00185 .

12. Schaufeli WB, Taris TW. A critical review of the job-demandsresources model: Implications for improving work and health. In: Bauer GF, Hämmig O, editors. Bridging Occupational, Organizational and Public Health: A Transdisciplinary Approach. Dordrecht: Springer; 2014. p. 43-68. http://dx.doi. org/10.1007/978-94-007-5640-3_4.

13. Park R, Searcy D. Job autonomy as a predictor of mental well-being: The moderating role of quality-competitive environment. J Bus Psychol. 2012;27:305-16. http://dx.doi. org/10.1007/s10869-011-9244-3.

14. Nijp HH, Beckers DGJ, Geurts SAE, Tucker P, Kompier MAJ. Systematic review on the association between worktime control and work-non-work balance, health and well-being, and job-related outcomes. Scand J Work Environ Health. 2012;38:299-313. http://dx.doi.org/10.5271/sjweh.3307.

15. Tausig M, Fenwick R. Unbinding time: alternate work schedules and work-life balance. J Fam Econ Issues. 2001;22:101-19. http://dx.doi.org/10.1023/A:1016626028720.

16. Schieman S, Young M. Is there a downside to schedule control for the work-family interface? J Fam Issues. 2010;31:1391414. http://dx.doi.org/10.1177/0192513X10361866.

17. Grice MM, McGovern PM, Alexander BH. Flexible work arrangements and work-family conflict after childbirth. Occup Med. 2008;58:468-74. http://dx.doi.org/10.1093/occmed/ kqn090.

18. Hanse JJ, Winkel J. Work organisation constructs and ergonomic outcomes among European forest machine operators. Ergonomics. 2008;51:968-81. http://dx.doi. org/10.1080/00140130801961893.

19. Eaton SC. If you can use them: flexibility policies organizational commitment, and perceived performance. Ind Relat. 2003;42(2):145-67. http://dx.doi.org/10.1111/1468$232 \mathrm{X} .00285$

20. Allen TD. Family-supportive work environments: the role of organizational perceptions. J Vocat Behav. 2001;58:414-35. http://dx.doi.org/10.1006/jvbe.2000.1774.

21. Kerkhofs M, Román A, Ester P. Flexibility profiles of European companies: European company survey 2009. Available from: www.eurofound.europa.eu/pubdocs/2010/60/en/1/ EF1060EN.pdf.

22. Matos K, Galinsky E. 2012 National study of employers. Available from: http://www.familiesandwork.org/2012national-study-of-employers/

23. Hansen AM, Nabe-Nielsen K, Albertsen K, Hogh A, Lund $\mathrm{H}$, Hvid H, Garde AH. Self-rostering and psychosocial work factors: A mixed methods intervention study. Appl Ergonomics. 2015;47:203-10. http://dx.doi.org/10.1016/j. 
apergo.2014.10.006.

24. Ingre M, Akerstedt T, Ekstedt M, Kecklund G. Periodic selfrostering in shift work: Correspondence between objective work hours, work hour preferences (personal fit), and work schedule satisfaction. Scand J Work Environ Health. 2012;38(4):327-36. http://dx.doi.org/10.5271/sjweh.3309.

25. Thornthwaite L, Sheldon P. Employee self-rostering for work-family balance: Leading examples in Austria. Employee Relat. 2004; 26(3):238-54. http://dx.doi. org/10.1108/01425450410530637.

26. Nabe-Nielsen K, Garde AH, Diderichsen F. The effects of work-time influence on health and well-being: A quasiexperimental intervention study among eldercare workers. Int Arch Occup Environ Health. 2011;84:683-95. http://dx.doi. org/10.1007/s00420-011-0625-8.

27. Garde AH, Albertsen K, Nabe-Nielsen K, Carneiro IG, Skotte $\mathrm{J}$, Hansen SM, et al. Implementation of self-rostering (the PRIO-project): Effects on working hours, recovery, and health. Scand J Work Environ Health. 2012;38(4):314-26. http:// dx.doi.org/10.5271/sjweh.3306.

28. Albertsen K, Persson R, Garde AH, Rugulies R. Psychosocial determinants of work-to-family conflict among knowledge workers with boudaryless work. Appl Psych-Health Wellbeing. 2010;2:160-81.

29. Allvin M, Aronsson G, Hagström T, Johansson G, Lundberg U. Work without boundaries: Psychological perspectives on the new working life. Chichester, UK: John Wiley \& Sons, Ltd; 2011. http://dx.doi.org/10.1002/9781119991236.

30. Kamp A, Lund HL, Hvid HS. Negotiating time, meaning and identity in boundaryless work. J Workplace Learn; 2011;23(4):229-42. http://dx.doi. org/10.1108/13665621111128655.

31. The importance of individual preferences when evaluating the associations between working hours and indicators of health and well-being. Nabe-Nielsen K, Kecklund G, Ingre M, Skotte J, Diderichsen F, Garde AH. Appl Ergonomics. 2010;41:77986. http://dx.doi.org/10.1016/j.apergo.2010.01.004.

32. Axelsson J, Åkerstedt T, Kecklund G, Lowden A. Tolerance to shift work: How does it relate to sleep and wakefulness? Int Arch Occup Environ Health. 2004;77:121-9. http://dx.doi. org/10.1007/s00420-003-0482-1.

33. Kecklund G, Eriksen CA, Åkerstedt T. Police officers attitude to different shift systems: Association with age, present shift schedule, health and sleep/wake complaints. Appl Ergonomics. 2008;39:565-71. http://dx.doi.org/10.1016/j. apergo.2008.01.002.

34. Sturman MC, Walsh K. Strengthening the employment relationship: The effects of work-hours fit on key employee attitudes. J Organiz Behav. 2014;35:762-84. http://dx.doi. org/10.1002/job.1925.

35. Barnett RC, Gareis KC, Brennan RT. Fit as a mediator of the relationship between work hours and burnout. J Occup Health Psychol. 1999;4(4):307-17. http://dx.doi.org/10.1037/10768998.4.4.307.

37. Åkerstedt T. Shift work and disturbed sleep/wakefulness.
Occup Med (Lond). 2003;53(2):89-94. http://dx.doi. org/10.1093/occmed/kqg046.

38. Bøggild H, Knutsson A. Shift work, risk factors and cardiovascular disease. Scand J Work Environ Health. 1999;25(2):85-99. http://dx.doi.org/10.5271/sjweh.410.

39. Knauth $P$, Hornberger $S$. Preventive and compensatory measures for shift workers. Occup Med (Lond). 2003;53(2):109-16. http://dx.doi.org/10.1093/occmed/kqg049.

40. Frost P, Kolstad HA, Bonde JP. Shift work and the risk of ischemic heart disease: A systematic review of the epidemiologic evidence. Scand J Work Environ Health. 2009;35:163-79. http://dx.doi.org/10.5271/sjweh.1319.

41. Nabe-Nielsen K, Quist HG, Garde AH, Aust B. Shiftwork and changes in health behaviors. J Occup Environ Med. 2011;53(12):1413-7. http://dx.doi.org/10.1097/ JOM.0b013e31823401f0.

42. Edwards JR. An examination of competing versions of the person-environment fit approach to stress. Acad Manage J. 1996;39:292-339. http://dx.doi.org/10.2307/256782.

43. Pervin LA. Performance and satisfaction as a function of individual-environment fit. Psychol Bull. 1968;69:56-68. http://dx.doi.org/10.1037/h0025271.

44. Koppes LLJ, de Vroome EMM, Mol MEM, Janssen BJM, van den Bossche SNJ. [Netherlands Working Conditions Survey 2010: Methodology and overall results] Nationale enquête arbeidsomstandigheden 2010: Methodologie en globale resultaten. Hoofddorp: TNO; 2011. Dutch.

45. Van Veldhoven MJPM, Sluiter JK. Work-related recovery opportunities: Testing scale properties and validity in relation to health. Int Arch Occup Environ Health. 2009;82:1065-75. http://dx.doi.org/10.1007/s00420-009-0411-z.

46. Geurts SAE, Taris TW, Kompier MAJ, Dikkers JSE, Van Hooff MLM, Kinnunen UM. Work-home interaction from a work psychological perspective: Development and validation of a new questionnaire, the SWING. Work Stress. 2005;19:319-39. http://dx.doi.org/10.1080/02678370500410208.

47. De Vries J, Michielsen H, Van Heck GL, Drent M. Measuring fatigue in sarcoidosis: The fatigue assessment scale (FAS). Brit J Health Psych. 2004;9:279-91. http://dx.doi. org/10.1348/1359107041557048.

48. Van Veldhoven M, Meijman T. [Measurement of psychosocial job demands with a questionnaire: The questionnaire experience and evaluation of work (VBBA)] Het meten van psychosociale arbeidsbelasting met eenvragenlijst: de Vragenlijst Beleving en Beoordeling van de Arbeid (VVBA). Amsterdam: NIA; 1994. Dutch.

49. Health disorders of shift workers. Knutsson, A. Occup Med 2003;53:103-8. http://dx.doi.org/10.1093/occmed/kqg048.

50. Hardardson $\mathrm{O}$. The flexibility of working time arrangements for women and men. Statistics in focus 96/2007. Luxembourg: Eurostat; 2007.

Received for publication: 17 September 2014 